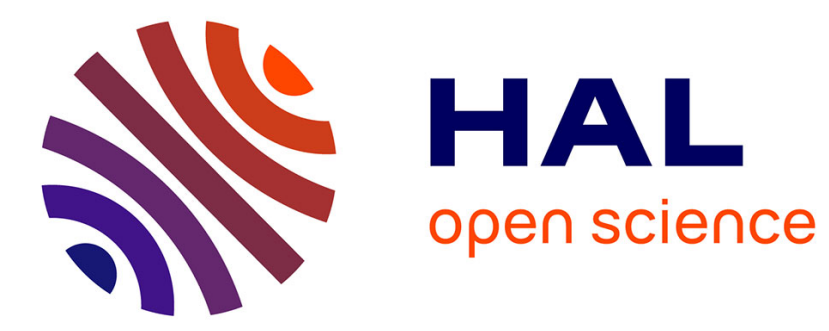

\title{
Environmental Tax and the Distribution of Income among Heterogeneous Workers
}

\author{
Mireille Chiroleu-Assouline, Mouez Fodha
}

\section{To cite this version:}

Mireille Chiroleu-Assouline, Mouez Fodha. Environmental Tax and the Distribution of Income among Heterogeneous Workers. Annales d'Economie et de Statistique, 2011, 103-104, pp.71-92. hal00652900

\section{HAL Id: hal-00652900 \\ https://hal-paris1.archives-ouvertes.fr/hal-00652900}

Submitted on 16 Dec 2011

HAL is a multi-disciplinary open access archive for the deposit and dissemination of scientific research documents, whether they are published or not. The documents may come from teaching and research institutions in France or abroad, or from public or private research centers.
L'archive ouverte pluridisciplinaire HAL, est destinée au dépôt et à la diffusion de documents scientifiques de niveau recherche, publiés ou non, émanant des établissements d'enseignement et de recherche français ou étrangers, des laboratoires publics ou privés. 


\title{
Environmental Tax and the Distribution of Income among Heterogeneous Workers
}

Annales d'Economie et de Statistique, n¹03-104, July-Decembre 2011, pp. 71-92.

Author Version

\author{
Chiroleu-Assouline, Mireille \\ Paris School of Economics - University Paris 1 Panthéon-Sorbonne \\ Fodha, Mouez \\ Paris School of Economics - University Paris 1 Panthéon-Sorbonne
}

\begin{abstract}
This paper analyzes the environmental tax policy issues when labor is heterogeneous. The objective is to assess whether an environmental tax policy could be Pareto improving, when the revenue of the pollution tax is recycled by a change in the labor tax properties. We show that, depending on the heterogeneity characteristics of labor and on the initial structure of the tax system, a policy mix could be designed in order to leave each class of workers unharmed. It consists of an increase in progressivity together with a decrease in the flat rate component of the wage tax.*
\end{abstract}

* JEL classification: D60 - D62 - E62 - H23.

* Keywords: Environmental tax - Heterogenous agents - Welfare analysis - Tax progressivity. 


\section{Introduction}

One of the most publicly debated issues about environmental regulation concerns its effects on the poorest agents and the fairness of such a policy. This question is being raised again because of the relative failure observed until now of the emissions trading system chosen as an instrument for the Greenhouse Gases (GHG) regulation, which explains the emergence of some new arguments in favor of a carbon tax. What would be the inequality consequences of the European Carbon Tax Project or of the Climate-Energy Contribution planned by the "Grenelle de l'environnement" in France? How could these consequences be smoothed or even eliminated? More generally, how is it possible to implement an environmental tax without inducing further inequalities? The economic literature does not contribute much to this debate and our paper aims to fill the existing gap.

The still open question "Can an environmental tax reform be designed without negatively affecting the economic welfare?" has given rise to a huge literature on the double dividend. Terkla [1984], Parry [1995], or Poterba [1993] first had the intuition that the recycling of the revenue of an environmental tax could reduce or even eliminate the gross cost of its implementation. As governments use the revenues from pollution taxes to decrease other distortionary taxes, environmental taxes may lead to a double dividend, according to Goulder's definition, by improving the environmental quality and achieving a less distortionary tax system (Goulder [1995]). Baumol and OAtes [1988], Pearce [1991] and OATES [1991] suggested that these efficiency gains could be a powerful argument in favor of environmental taxation. After some prior refutations of the double dividend hypothesis (BovenberG and DE MooiJ [1994] and their followers), Goulder [1995] and LigTHART [1998] showed that the existence of the double dividend essentially depends on the possibility of transferring the global tax burden from the wage earners to some fixed production factors or to other consumers, thus emphasizing the role of heterogeneity. Following this line, Chiroleu-Assouline and Fodha [2005] and [2006] studied the existence conditions of a long term double dividend, taking into account the distinction between wage earners and retired consumers, by means of OLG models.

Surprisingly enough, although this large body of literature has deeply analyzed the double dividend issue, it has neglected the distribution issue of the welfare gain, although it is usually obtained at the expense of some groups of agents. It is well known that the costs and benefits of environmental policies are unequally distributed among agents. The 
rich and the poor seem to assign different degrees of priority to environmental protection (BAUMOL and OATES[1988]), since wealthier individuals would accept paying for a higher level of environmental quality (considered as a normal good). Beyond this fact, distributive elements also matter when we consider how the costs of a policy of environmental protection are likely to be distributed among individuals with differing incomes. Most existing studies are empirical works dealing mainly with the distribution of the benefits of the environmental policies among income classes (CHRistainsen and TIETENBERG [1985], Elliott et al. [1985], Harrison [1995], Peskin [1978]), and neglecting the cost side of the policies. One can infer from some empirical studies emphasizing the regressivity of the indirect taxes, that any environmental policy is likely also to be regressive. In particular, in the French case, a tax on energy or transport consumption harms the lowest wage households three times more than the highest wage households (RUIZ and TRANNOY [2008]). Moreover, the usual recycling of the environmental tax revenues through a decrease in the labor tax rate could also be regressive (METCALF [1999]). This point is of interest in a world in which inequality has assumed high priority among social issues. Policies and programs that are perceived as unfair will stand little prospect of passage even if they enhance the prospects for efficiency and sustainability.

Is it then possible to design an environmental policy in order to ensure a non-decreasing welfare for each class of workers? Compared to the standard double dividend literature which pursues two objectives in a second-rank framework - improve the environment by increasing an environmental tax (first dividend) and the economic welfare by decreasing another distorsive tax (second dividend) - we add the third objective of Pareto improvement. It corresponds to an acceptability/unanimity criterion for the policy when agents are heterogenous. Three instruments are consequently needed: we argue that the distributive properties of the tax policy could be one of the instruments of fair internalization of the environmental externalities ${ }^{1}$. The aim of this paper is therefore to design a balanced environmental tax reform able to correct these regressive properties of taxes and to leave all classes of worker better off.

We assume capital-intensive sectors to be polluting sectors. To keep things simple, as we deal only with a one sector aggregate output, we assume that capital input is the main

\footnotetext{
${ }^{1}$ In line with the double dividend literature, we are not seeking for the optimal tax system, which would require to use several instruments in order to internalize the externalities. Nevertheless, according to our Pareto-improving criterion, our results give conditions such that the economy gets closer to its Pareto optimal equilibrium.
} 
source of pollution (even if it is only a proxy). The key factor is that capital accumulation favors the production of pollution-intensive goods. For industrial pollution, this is consistent with evidence (Brown et al. [1992], Gale and Mendez [1998], Antweiler et al. [2001]). Indeed, Brown et al. [1992] show that a 10\% change in the Mexican capital stock induces a $9 \%$ increase in electric utility output. The conclusion they draw is simply that electricity generation is highly capital intensive, and this creates a strong ling between capital accumulation and sulfur dioxide pollution. In the same way, the empirical work of GALE and Mendez [1998] investigate the role that capital abundance may play in predicting cross-country differences in pollution levels. It suggests a strong link beween factor endowments and pollution level. Finally, Antweiler et al. [2001] find that a 1\% increase in a nation's capital-to-labor ratio, holding scale, income, and other determinants constant, leads to perhaps a one percentage point increase in pollution.

Our model shares the mean features of Chiroleu-Assouline and Fodha [2005] and [2006]. As in Chaо and Peck [2000] or Williams [2002] or [2003], we assume that the degradation of environmental quality has a negative impact on the total productivity of factors. This assumption is justified by the results of an increasing number of empirical studies measuring the health effects of pollution (OECD [2008]) and the impact of the health of workers on labor productivity (BLOOM et al. [2004], in a sample consisting of both developing and industrial countries, found that good health, proxied by life expectancy, has a sizable, positive effect on economic growth). Since Ostro [1983], many papers have emphasized the loss of productivity caused by the health effects of pollution, e.g. SAmakovlis et al. [2005], or Pervin et al. [2008] for air-pollution, and also Bosello et al. [2006] or HÜBLER et al. [2008] for the health effects of climate change. For example, according to BosELlo et al. [2006], strong heat stress causes a productivity loss of $3 \%$ and extreme heat a loss of $12 \%$. Another source of productivity loss originates in the impact of pollution on the quality of natural resources (GOLLOP and SwINAND [1998] for the agricultural sector $)^{2}$.

We assume that the production technology is a function of capital and heterogeneous labor. Heterogeneous workers live two periods (young and old) and earn wages correspond-

\footnotetext{
${ }^{2}$ Our model adresses the specific issue of pollutions due to industrial, highly capital-intensive sectors, that emit fine particles, NOx or SOx. These pollutants are harmmful for the health of all agents, and especially of the workers employed by these sectors. As an anonymous referee pointed out, this stylized model can not describe the GHG case, since the dioxyde emissions have no direct effect on the health and productivity of workers and they are due to the use of fossil energies which can be susbsituted by carbon free inputs, such as capital or knowledge.
} 
ing to their skill and consequently to their productivity. The labor tax is a very general one that could be either a progressive or proportional tax. Our demographic assumptions allow us to take into account several income classes; indeed, we consider (i) the heterogeneity characteristics of the labor market (high wages - skilled workers, middle wages, low wages - non skilled workers...), (ii) the heterogeneity of the individual income sources (wages for workers, savings for retirees). The environmental policy consists of increasing the environmental tax on savings, in a second-rank framework. We then characterize the necessary conditions for the obtaining of a double dividend, i.e. an improvement of the environmental quality and an improvement of the welfare when the revenue of the pollution tax is recycled by a change in the labor tax rates. Previous studies show that the obtaining of a double dividend requires economic conditions such that the double dividend hypothesis seems unrealistic. Conversely, we show that the conditions for the obtaining of a double dividend lie in the distributive properties of the labor taxes. Even when the double dividend is not possible, the cost of the pollution regulation can be minimized by a new designing of the progressivity of the labor tax instead of an homogenous cut in the labor tax rates. The results are dependent on the initial tax system.

The paper is organized as follows. Section 2 presents the model and Section 3 presents the welfare analysis of a tax policy. Section 4 gives the specification of the balanced tax reform. In Section 5 we present the environmental effects of the tax reform and Section 6 examines the welfare effects of such a reform. Section 7 presents some empirical illustrations and the last section concludes.

\section{The Model}

We consider an overlapping generations economy with polluting technology of production i.e. with polluting capital. Heterogeneous workers live two periods (young and old) and earn wages corresponding to their skill and consequently to their productivity ${ }^{3}$. We assume that $N_{t}$ individuals are born in period $t$ and that the population remains constant, so we can normalize $N_{t}$ to unity. Each household is characterized by its labor class (or skill) $i$. There are $I$ classes of agents in the economy $(i$ and $I \in \mathbb{N}$ ), and the size of each

\footnotetext{
${ }^{3}$ In our very stylized model, the heterogeneity of workers derives, by assumption, from their skills. In our case, because the utility function is logarithmic, this model is equivalent to a model with endogenous work supply and heterogenous desutilities of work. We thank an anonymous referee to have drawn our attention to this equivalence.
} 
class $i$ is equal to $q_{i}$ (with $\sum_{i=1}^{I} q_{i}=1$ ). Each agent supplies one unit of labor ${ }^{4}$ when she is young and earns a wage $w_{t}^{i}$; she divides her labor income between consumption and savings $s_{t}^{i}$. The sub-optimal initial tax system is composed by an income tax and an environmental tax intended to finance the public expenditures $G$. The income (or labor) tax is a very general one that could be either a progressive or proportional tax as the labor tax rate is $\tau^{i} \in[0,1$. In the second period the household consumes her savings and the interest she earns. The welfare of an individual born at $t$ is measured with the intertemporal separable utility function ${ }^{5}$ :

$$
U\left(c_{t}^{i y}, c_{t+1}^{i o}\right)=(1-\eta) \ln c_{t}^{i, y}+\eta \ln c_{t+1}^{i, o}
$$

with $c_{t}^{y}$ denoting the first-period consumption of the agent born at $t, c_{t+1}^{o}$ her secondperiod consumption. $\eta \in] 0,1[$ represents the individual propensity to save. The two instantaneous components of the utility function obviously exhibit the usual properties: they are increasing in their argument, strictly concave and satisfy the Inada conditions. The real interest rate is $r_{t+1}$. As the capital is polluting, the environmental policy consists in a tax on savings $\tau^{e} \in[0,1[$. The household's budget constraints writes:

$$
\left\{\begin{array}{c}
\left(1-\tau_{t}^{i}\right) w_{t}^{i}=c_{t}^{i y}+\left(1+\tau_{t}^{e}\right) s_{t}^{i} \\
c_{t+1}^{i o}=\left(1+r_{t+1}\right) s_{t}^{i}
\end{array}\right.
$$

The household's problem is to choose her consumption path to maximize her lifetime utility subject to the intertemporal budget constraint.

This yields the optimal consumption and savings path of the representative household, within the Diamond framework (Diamond [1965]) with a homothetic utility function:

$$
\left\{\begin{array}{l}
c_{t}^{i y}=(1-\eta)\left(1-\tau_{t}^{i}\right) w_{t}^{i} \\
c_{t+1}^{i o}=\eta \frac{\left(1+r_{t+1}\right)}{\left(1+\tau_{t}^{e}\right)}\left(1-\tau_{t}^{i}\right) w_{t}^{i} \\
s_{t}^{i}=\eta \frac{\left(1-\tau_{t}^{i}\right)}{\left(1+\tau_{t}^{e}\right)} w_{t}^{i}
\end{array}\right.
$$

\footnotetext{
${ }^{4}$ Our long term view allows us to assume full employment. Moreover, we focus on the efficiency double dividend (according to Goulder [1995]) and not on the employment double dividend.

${ }^{5}$ We do not introduce any direct effect of pollution on the household's welfare, but only the indirect one through the consequences on productivity of the degradation of environmental quality (see below). Indeed the direct effect would have no impact on the welfare distribution among heterogenous agents while the indirect one affects the wage gaps, because agents do not differ here by their preferences.
} 
The production sector consists of many firms, each of them being characterized by the same Cobb-Douglas production function $F(\cdot)$ with constant returns to scale. They use different kinds of labor (high wages - skilled workers, middle wages, low wages - non skilled workers) and the total productivity of factors $A\left(P_{t}\right)$ is negatively affected by pollution $P_{t}$ because pollution degrades the health of workers or the quality of natural resources $\left(A(P)=P^{-e}\right.$ with $\left.e>0\right)$ :

$$
Y_{t}=A\left(P_{t}\right) F\left(K_{t}, L_{i, t}\right)=A\left(P_{t}\right) K_{t}^{\lambda} \prod_{i=1}^{I} L_{i, t}^{\alpha_{i}}
$$

where $\lambda>0$ and $\alpha_{i} \geq 0$ stand for the shares of the input factors in production, $\lambda+\Sigma \alpha_{i}=1$.

The maximization problem of the representative firm is (taking the output price as numeraire):

$$
\underset{K,\left\{L_{i}\right\}}{\operatorname{Max}} \quad \pi_{t}=A\left(P_{t}\right) K_{t}^{\lambda} \prod_{i=1}^{I} L_{i, t}^{\alpha_{i}}-\sum_{i=1}^{I} w_{t}^{i} L_{i, t}-\left(1+r_{t}\right) K_{t}
$$

with $\pi_{t}$ the current net revenue, $w_{t}^{i}$ the real wage rate of class $i$ of workers. The depreciation rate of capital is equal to unity.

Since markets are competitive, capital and labor earn their marginal products:

$$
\left\{\begin{array}{l}
\frac{\lambda Y_{t}}{K_{t}}=1+r_{t} \\
\frac{\alpha_{i} Y_{t}}{L_{i, t}}=w_{t}^{i}
\end{array}\right.
$$

This yields, at the equilibrium of the labor markets:

$$
Y_{t}=A\left(P_{t}\right) K_{t}^{\lambda} \prod_{i=1}^{I} q_{i}^{\alpha_{i}}
$$

The ratio of wages is (using 3):

$$
\frac{w_{t}^{i}}{w_{t}^{1}}=\frac{\alpha_{i}}{\alpha_{1}} \frac{q_{1}}{q_{i}}
$$

Assumption 1: The different labor classes are ranked by growing skills, i.e. by growing wages:

$$
w_{t}^{i}>w_{t}^{i-1} \Leftrightarrow \frac{\alpha_{i}}{q_{i}}>\frac{\alpha_{i-1}}{q_{i-1}}
$$


We assume that government spending $(G)$ is entirely financed by current taxes. The government's budget constraint states that, at each period, its purchases must be equal to its tax revenues generated by the pollution tax and the labor tax:

$$
\sum_{i=1}^{I} q_{i} \tau_{t}^{i} w_{t}^{i}+\tau_{t}^{e} \sum_{i=1}^{I} q_{i} s_{t}^{i}=G_{t}
$$

We define a progressivity index of the labor tax, $a_{i}=a b(i)$, such as:

$$
\tau^{i}=\tau^{1}+a_{i}=\tau^{1}+a b(i)
$$

where $\tau^{1}$ is the flat component of the tax rate and $a$ is a positive parameter. Assume $b(1)=0$ and $b(i+1)>b(i) \quad \forall i>1$. We consider the general case for the characteristics of the tax progressivity ${ }^{6}$. For example, the design of progressivity fits well the characteristics of the French tax system when $b(i+2)-b(i+1)<b(i+1)-b(i)$.

This yields

$$
\sum_{i=1}^{I} q_{i} \tau^{i} w^{i}=\sum_{i=1}^{I} \tau^{i} \alpha_{i} Y=Y\left(\tau^{1}(1-\lambda)+a \sum_{i=1}^{I} b(i) \alpha_{i}\right)
$$

Let us define $B_{I}$ as the $\operatorname{sum} \sum_{i=1}^{I} b(i) \alpha_{i} . \quad B_{I}>0$ is constant for any given $I$ and progressivity characteristics $\{b(i)\}_{1 \leq i \leq I}$.

The pollution flow is due to the capital stock, and we assume that the welfare is affected by the stock of pollution only through its effect on the total factor productivity. The dynamics of pollution are described by the following equation:

$$
P_{t}=(1-h) P_{t-1}+\phi K_{t-1}
$$

where $h$ is the constant rate of natural absorption of pollution $(0<h<1)$ and $\phi>0$ stands for the emission rate of pollutants.

The equilibrium condition of the capital market, meaning that the capital stock in period $t+1$ is the amount saved by young individuals in period $t$, is obtained by substituting

\footnotetext{
${ }^{6}$ Unlike the usual specification of the tax progressivity in the literature, we assume here that $\tau^{i}$ depends on the class $i$ of the agent and do not depend directly on the wage $w^{i}$. As assumption 1 implies a ranking between $i$ and $w^{i}$, our definition of the tax progressivity is nearly, but not exactly equivalent to the usual one, since it relies here on an ordinal concept rather than on a cardinal one, as usual.
} 
the zero-profit condition, the government's budget constraint (eq. 5) and the household's budget constraints (eq. 1) into the equilibrium of the output good market. It writes:

$$
K_{t}=\sum_{i=1}^{I} q_{i} s_{t-1}^{i}
$$

By substituting eq. 2:

$$
K_{t}=\frac{\eta}{1+\tau_{t-1}^{e}} \frac{q_{1}}{\alpha_{1}}\left[\left(1-\tau_{t-1}^{1}\right)(1-\lambda)-a B_{I}\right] w_{t-1}^{1}
$$

and using eq. 3, we finally obtain:

$$
K_{t}=\frac{\eta}{1+\tau_{t-1}^{e}}\left[\left(1-\tau_{t-1}^{1}\right)(1-\lambda)-a B_{I}\right] Y_{t-1}
$$

\section{The steady-state}

A steady state equilibrium is an allocation where capital and pollution are stationary, i.e. $K^{*}$ and $P^{*}$ are such that (using eq. 6 and by substitution of eq. 4 in eq. 8):

$$
\begin{gathered}
K^{*}=\left[\frac{\eta}{1+\tau^{e}} X A\left(P^{*}\right) \prod_{i=1}^{I} q_{i}^{\alpha_{i}}\right]^{\frac{1}{1-\lambda}} \\
P^{*}=\frac{\phi}{h} K^{*}
\end{gathered}
$$

with $X=\left(1-\tau^{1}\right)(1-\lambda)-a B_{I}$, constant for a given tax system.

It is easy to verify that $X$ is always strictly positive, which ensures the existence of a positive steady-state equilibrium. $X>0$ reduces to $b(\tilde{\imath})<\frac{1-\tau^{1}}{a}$ where $\tilde{\imath}$ is the particular class of worker ${ }^{7}$ such that $b(\tilde{\imath})=\frac{\Sigma_{1}^{I} b(i) \alpha_{i}}{\Sigma_{1}^{I} \alpha_{i}}$. Hence $b(\tilde{\imath})$ is the average of the coefficients of progressivity, weighted by the shares of each class of worker in the output. $X>0$ is then equivalent to $\tau^{\tilde{\imath}}=\tau^{1}+a b(\tilde{\imath})<1$, meaning that the revenue of this particular class is not totally confiscated. This is always verified since we assumed that $\tau^{i}<1 \quad \forall i$.

The following proposition characterizes the steady state of this model.

\footnotetext{
${ }^{7}$ More precisely, $b(\tilde{\imath}) \geq \frac{\Sigma_{1}^{I} b(i) \alpha_{i}}{\Sigma_{1}^{I} \alpha_{i}}$ and $b(\tilde{\imath}-1)<\frac{\Sigma_{1}^{I} b(i) \alpha_{i}}{\Sigma_{1}^{I} \alpha_{i}}$, with $\tilde{\imath} \leq I$.
} 
Proposition 1 For given initial conditions $\left\{K_{0}, K_{-1}, P_{-1}\right\}$ and for a given triplet of tax policy instruments, $\left\{\tau^{e}, \tau^{1}, a\right\}$, the equilibrium conditions can be summed up by eq. $(2),(3),(5),(6),(8)$. Thus, there exists a locally stable steady-state defined by $\left(K^{*}, P^{*}\right)$ such that:

$$
\begin{aligned}
K^{*} & =\left(\frac{\eta}{1+\tau^{e}} X\right)^{\frac{1}{1-(\lambda-e)}}\left[\left(\frac{\phi}{h}\right)^{-e} \prod_{i=1}^{I} q_{i}^{\alpha_{i}}\right]^{\frac{1}{1-(\lambda-e)}} \\
P^{*} & =\frac{\phi}{h}\left(\frac{\eta}{1+\tau^{e}} X\right)^{\frac{1}{1-(\lambda-e)}}\left[\left(\frac{\phi}{h}\right)^{-e} \prod_{i=1}^{I} q_{i}^{\alpha_{i}}\right]^{\frac{1}{1-(\lambda-e)}}
\end{aligned}
$$

Proof. See above for the definition of the capital market equilibrium. Moreover, (i) the utility function is homothetic, (ii) the utility and the production functions verify the Inada conditions, (iii) $F_{K}^{\prime \prime}<0$, (iv) $\lim _{K \rightarrow 0}\left(F_{K}^{\prime} . K / F(K)\right) \in[0,1[$. Conditions $(i)-(i v)$ ensure the existence of the steady-state equilibrium (see DE LA CROIX and MicheL [2002] and Konishi and Perera-Tallo [1997]). Concerning local stability, we show that the steady state associated with the dynamic system, $(6,8)$, is a sink (see Appendix).

Using Proposition 1 and eq. 9, one obtains the output value at the steady-state equilibrium:

$$
Y^{*}=\left(\frac{\eta}{1+\tau^{e}} X\right)^{\frac{\lambda-e}{1-(\lambda-e)}}\left[\left(\frac{\phi}{h}\right)^{-e} \prod_{i=1}^{I} q_{i}^{\alpha_{i}}\right]^{\frac{1}{1-(\lambda-e)}}
$$

Assumption 2: $\lambda-e>0$.

It means that the direct contribution of capital to output $(\lambda)$ is greater than the indirect one through pollution and productivity $(e)^{8}$.

In the rest of the paper, we will only consider the consequences of variations of the tax rates on the steady-state equilibrium defined in Proposition 1 . The existence of the new steady-state is ensured if and only if $X$ remains positive, i.e. $\tau^{\tilde{\imath}}+d \tau^{\tilde{\imath}}<1$. Notice that $X$ may remain positive even if some high wages classes bear a tax rate equal or greater than unity. A sufficient condition to ensure the positivity of $X$ after the tax reform is that $d X>0$, i.e. that the variations of the labor tax components verify $-\frac{d a}{d \tau^{1}}<\frac{1-\lambda}{B_{I}}, \forall d \tau^{e}>0$.

\section{Welfare Analysis}

\footnotetext{
${ }^{8}$ The reverse $(\lambda<e)$ would simplify the analysis but this case would be of negligible economic interest because any rise in $\tau^{e}$ would result in a decrease of $K$ allowing an increase of $Y$.
} 
Like Chiroleu-Assouline and Fodha [2006], we examine here the welfare effects of the tax change for a generation during its life-cycle, once the final steady-state equilibrium is reached. In this section, the welfare issue is thus a long term one.

One can measure the welfare effects of small tax changes by the marginal excess burden. It corresponds to the additional income that needs to be provided to the representative household to keep her utility at its initial level: this is the compensatory income variation, denoted $d R$. It stands for the excess welfare loss of the consumers over and above the tax revenues collected by the government and can be interpreted as the hidden costs of financing public spending: a positive value for the marginal excess burden indicates a loss in welfare after the tax reform.

Let us determine the compensatory income variation which, after the tax reform, would leave the level of life-cycle utility unchanged $(d U=0)$ :

$$
\begin{gathered}
\frac{\partial U}{\partial c^{i y}} d c^{i y}+\frac{\partial U}{\partial c^{i o}} d c^{i o}=0 \\
\Longleftrightarrow \frac{(1+r)}{\left(1+\tau^{e}\right)} d c^{i y}+d c^{i o}=0
\end{gathered}
$$

The intertemporal budget constraint of household $i$ writes:

$$
\left(1-\tau^{i}\right) w^{i}=c^{i y}+\frac{\left(1+\tau^{e}\right)}{(1+r)} c^{i o}
$$

Remember that

$$
c^{i o}=\frac{\eta}{(1-\eta)} \frac{(1+r)}{\left(1+\tau^{e}\right)} c^{i y}
$$

We use the first-order conditions of the representative household's program and the definition of the compensatory income variation $d R$ :

$$
\begin{aligned}
\left(1-\tau^{i}\right) d w^{i}-w^{i}\left(d \tau^{1}+b(i) d a\right)+d R^{i} & =d \hat{c}^{i y}-\frac{\hat{c}^{i o}}{(1+r)^{2}} d r+\frac{\hat{c}^{i o}}{(1+r)} d \tau^{e}+\frac{\left(1+\tau^{e}\right)}{1+r} d \hat{c}^{i o} \\
& =-\frac{\left(1+\tau^{e}\right) \hat{c}^{i o}}{(1+r)^{2}} d r+\frac{\hat{c}^{i o}}{(1+r)} d \tau^{e}
\end{aligned}
$$

this leads to:

$$
d R^{i}=-\left(1-\tau^{i}\right) d w^{i}+w^{i}\left(d \tau^{1}+b(i) d a\right)-\frac{\left(1+\tau^{e}\right) \hat{c}^{i o}}{(1+r)^{2}} d r+\frac{\hat{c}^{i o}}{(1+r)} d \tau^{e}
$$

Unlike Bovenberg and De Moitu [1994] and the greater part of the literature on this subject, it is here impossible to distinguish an environmental component and a nonenvironmental one, because pollution and production affect each other. In this paper, we 
are thus constrained to depart from the usual definition of the double dividend (GoULDER [1995]) because of this non-separability: a double dividend will be characterized by the simultaneous decrease of pollution (which stands for the usual first dividend) and increase of economic welfare (which depends here also on the pollution level).

The increase of welfare is verified for any variations of consumptions such that $\eta d c^{y} / c^{y}+$ $(1-\eta) d c^{o} / c^{o}>0$. This property plays an important role in our results. The first dividend requires a decrease of the capital stock inducing a decrease of the output, but this does not prevent the obtaining of the economic dividend. This originates in the opposite impacts of $d K$ on $w$ and $r: d w / d K>0$ and $d r / d K<0$.

Proposition 2 The increase of the environmental tax is regressive i.e. it more heavily penalises the lowest wage-earners.

Proof. Let us compute the steady-state value of the compensatory income variation for agent $i$ :

$$
\begin{aligned}
\frac{d R^{i}}{\frac{\alpha_{i}}{q_{i}} Y^{*}}= & Z \frac{\left(1-\tau^{i}\right)}{\left(1+\tau^{e}\right)} d \tau^{e} \\
& +\left[(Z-\eta) \frac{(1-\lambda)}{X}+\frac{1}{\left(1-\tau^{i}\right)}\right]\left(1-\tau^{i}\right) d \tau^{1} \\
& +\left[(Z-\eta) \frac{B_{I}}{X}+\frac{b(i)}{\left(1-\tau^{i}\right)}\right]\left(1-\tau^{i}\right) d a
\end{aligned}
$$

with $Z=\frac{\lambda-e}{1-(\lambda-e)}>0$.

Notice that from the optimality conditions of the firm (eq. 3) and the equilibrium condition of the labor market, we have $\frac{\alpha_{i}}{q_{i}} Y^{*}=w^{i *}$. Hence, when $d \tau^{1}=d a=0$, one obtains, for any environmental tax increase $d \tau^{e}>0$ :

$$
\frac{d R^{i}}{w^{i *}}=Z \frac{\left(1-\tau^{i}\right)}{\left(1+\tau^{e}\right)} d \tau^{e}>0
$$

then, as $Z>0, d R^{i}>0$ for every $i$. But $d R^{i} / w^{i *}$ is smaller when $\tau^{i}$ is higher (i.e. $i$ is also high) and when $w^{i *}$ is higher. When the environmental policy harms the consumers, the relative burden is greater for the less skilled ${ }^{9}$.

\footnotetext{
${ }^{9}$ This result does not rely on the usual channels causing the regressivity of an environmental tax. Indeed, as preferences are identical among agents, their savings rate and their budget share for polluting goods are the same. Our regressivity property results from the progressivity characteristics of the labor tax.
} 
The consequences of the increase of the environmental tax $\tau^{e}$ are clearly harmful for all the agents as it implies a decrease of the second-period consumption without any positive effect on the first-period one. Concerning the labor tax, its impact is ambiguous, for the flat component as well as for the progressivity index. This is because the decrease of the income of the agents could be compensated by an increase of the interest rate raising the consumption of the old agents. This latter effect increases with $\eta$.

\section{The Specification of the Balanced Tax Reform}

We assume an exogenous increase of the environmental tax rate, imposed by the government in order to control pollution. The amount of government spending is assumed $e x$ post invariant, and the tax policy has to maintain the amount of the tax revenues constant ${ }^{10}$. This increase $d \tau^{e}$ of the environmental tax rate can be accompanied by a variation of the labor tax rates $d \tau^{i}$ by two potential means: a homogenous variation of all labor tax rates through the flat rate component $\left(d \tau^{1}\right)$ or a variation in the progressivity of the labor tax $\left(d a_{i}\right.$ through a variation of $\left.a\right)$. At the steady-state equilibrium, the government's budget constraint is:

$$
\left(\tau^{1}(1-\lambda)+a B_{I}\right) Y^{*}+\tau^{e} K^{*}=G^{*}
$$

The link between the variations of the pollution tax and of the characteristics of the labor tax is obtained through the differentiation of this constraint, which is quite direct (using eq. 12).

Any balanced tax reform is then characterized by the following relationship between $d \tau^{e}, d \tau^{1}$ and $d a\left(\right.$ with $\left.d G=d q_{i}=d \alpha_{i}=0\right)$ :

$$
(1-\lambda) d \tau^{1}+B_{I} d a=-\frac{(\eta+\Psi)}{(1+\Psi)} X \frac{d \tau^{e}}{1+\tau^{e}}
$$

where $\Psi=-\left(\left(\tau^{1}(1-\lambda)+a B_{I}\right)+\frac{K^{*}}{Y^{*}} \frac{1}{(\lambda-e)} \tau^{e}\right) \frac{Z}{X} \leq 0$ (with $X>0$ ), constant.

\footnotetext{
${ }^{10}$ As noticed previously, this tax reform does not constitute the optimal one. Seeking for optimality would require to take into account the intergenerational externality on capital accumulation (dynamic efficiency) and the environmental externality. These two externalities would be corrected by the use of our two taxes. Concerning the distribution of welfare among the agents, we have to consider intergenerational and intragenerational characteristics. Intergenerational optimality considerations turn to the very general debate about the choice of the discount rate. But in our very simple model, the heterogeneity of workers is not an externality and would not deserve any correction. Intragenerational welfare would be the sum of the welfare of each class weighted by its size.
} 
We will study two polar cases for balancing this environmental tax reform:

- uniform variation of all labor tax rates, with invariant progressivity $(d a=0)$ :

$$
d \tau^{1}=-\frac{(\eta+\Psi)}{(1+\Psi)} \frac{X}{(1-\lambda)} \frac{d \tau^{e}}{1+\tau^{e}}=-\Lambda d \tau^{e}
$$

- variation of the progressivity, with invariant flat rate component of the tax rate $\left(d \tau^{1}=0\right)$ :

$$
d a=-\frac{(\eta+\Psi)}{(1+\Psi)} \frac{X}{B_{I}} \frac{d \tau^{e}}{1+\tau^{e}}=-\Omega d \tau^{e}
$$

Proposition 3 The sign of the balanced tax reform multipliers $\Lambda$ and $\Omega$ is a priori undetermined and depends on the initial tax rates and on the values of the various elasticities.

Proof. (i) The numerator measures the effect of the change in pollution tax rate on its revenue. There are both a value effect (the tax revenue increases with the tax rate, for unchanged stock of capital), summed up by $\Psi$, and a tax base effect (the stock of capital decreases, and so does the output; as the tax rate increases, so the tax base erodes), conditioned by $\eta$, which work in opposite ways. As a result, this term might be positive (if $\Psi>-\eta$ ) or negative.

(ii) The denominator measures the effect of the change in labor tax rate on its revenue. There are also both a value effect proportional to $\Psi$ (the tax revenue increases with the tax rate, for unchanged wages) and a tax base effect (the wages decrease as the tax rate increases, thus the tax base erodes) which work in opposite ways. As a result, this term too might be positive or negative (if $\Psi>-1$ ).

As the signs of the numerator and of the denominator are undetermined, the sign of the necessary change in the labor tax components is also undetermined.

Assumption 3: We only consider the Laffer-efficiency case, where the sign of the balanced tax reform multipliers $\Lambda$ and $\Omega$ is positive.

Under eq. 15, Assumption 3 implies $\frac{\eta+\Psi}{1+\Psi}>0 \Leftrightarrow-\Psi>1$ or $-\Psi<\eta$.

\section{The Environmental Effects of the Tax Reform}

As steady-state pollution depends only on steady-state capital, we find straightforward that the first dividend (i.e. a decrease of pollution) is reached if $d P^{*}=\frac{\phi}{h} d K^{*}<0$. This 
condition rewrites (see Proposition 1):

$$
\frac{d K^{*}}{K^{*}}=-\frac{1}{1-(\lambda-e)}\left[\frac{d \tau^{e}}{1+\tau^{e}}+\frac{(1-\lambda) d \tau^{1}+B_{I} d a}{X}\right]<0
$$

As $1-(\lambda-e)>0$, this condition reduces to $\frac{d \tau^{e}}{1+\tau^{e}}+\frac{(1-\lambda) d \tau^{1}+B_{I} d a}{X}>0$. We then have the two cases corresponding to the two alternative policies:

- invariant progressivity $(d a=0): \frac{d \tau^{e}}{1+\tau^{e}}>\frac{(1-\lambda) \Lambda d \tau^{e}}{X}$

- variation of the progressivity $\left(d \tau^{1}=0\right): \frac{d \tau^{e}}{1+\tau^{e}}>\frac{B_{I} \Omega d \tau^{e}}{X}$.

We obtain a first dividend if the multipliers are not too high:

$$
\left\{\begin{array}{l}
\Lambda<\frac{X}{\left(1+\tau^{e}\right)(1-\lambda)} \\
\Omega<\frac{X}{\left(1+\tau^{e}\right) B_{I}}
\end{array} \Longleftrightarrow \frac{\eta+\Psi}{1+\Psi}<1\right.
$$

This means that the decrease of the labor tax (either of the flat rate component or of the progressivity index) should be not too great in order not to jeopardize the environmental benefit of the reform.

Assumption 4: We only consider the case where the tax policy decreases pollution.

Proposition 4 Under Assumptions (1-4), the tax policy is efficient and reduces pollution if and only if the initial environmental tax rate is not too high: $\tau^{e}<1 / Z$.

Proof. We have to examine the two cases which verify the tax efficiency assumption (Ass. $3)$.

If $(i): 1<-\Psi$, then $\frac{\eta+\Psi}{1+\Psi}<1 \Leftrightarrow \eta>1$ : which conflicts with the basic assumption on $\eta$. The environmental benefit can never be achieved.

If $(i i):-\Psi<\eta$, then $\frac{\eta+\Psi}{1+\Psi}<1 \Leftrightarrow \eta<1$ : always verified.

Finally, such that to reach the first dividend under the tax efficiency assumption, one needs to impose $-\Psi<\eta$, which is a necessary and sufficient condition. This condition is met if and only if:

$$
\begin{aligned}
& \left(\left(\tau^{1}(1-\lambda)+a B_{I}\right)+\frac{\eta}{1+\tau^{e}} X \frac{1}{(\lambda-e)} \tau^{e}\right) \frac{Z}{X}<\eta \\
\Leftrightarrow \quad & \tau^{1}(1-\lambda)+a B_{I}+\frac{\tau^{e}}{1+\tau^{e}} X \frac{1}{(\lambda-e)} \eta<\eta \frac{X}{Z}
\end{aligned}
$$


which implies

$$
\begin{aligned}
& \frac{\tau^{e}}{1+\tau^{e}} X \frac{1}{(\lambda-e)} \eta<\eta \frac{X}{Z} \\
\Leftrightarrow \quad & (\lambda-e)<\frac{1}{1+\tau^{e}} \\
\Leftrightarrow \quad & \tau^{e}<\frac{1-(\lambda-e)}{\lambda-e}
\end{aligned}
$$

QED.

\section{The Welfare Effects of the Tax Reform}

As each policy does not affect all classes equally, one can wonder which one will be preferred by each class of worker.

Proposition 5 (i) The environmental tax reform preferred by the workers of the lowest classes consists of a decrease in the flat rate component of the tax rate $\tau^{1}(i i)$ but the one preferred by the workers of the highest classes consists of a decrease in the progressivity of the wage tax rate.

Proof. Let us compare the compensatory income variations associated with each policy.

- First case $\left(d R_{\left(\tau^{1}\right)}^{i}\right)$ : uniform variation of all labor tax rates (with invariant progressivity): $d a=0$ and $d \tau^{1}=-\Lambda d \tau^{e}$

$$
\begin{aligned}
\frac{d R_{\left(\tau^{1}\right)}^{i}}{\frac{\alpha_{i}}{q_{i}} Y^{*}}= & Z \frac{\left(1-\tau^{i}\right)}{\left(1+\tau^{e}\right)} d \tau^{e} \\
& -\left[\frac{(Z-\eta)}{X}(1-\lambda)+\frac{1}{\left(1-\tau^{i}\right)}\right]\left(1-\tau^{i}\right) \Lambda d \tau^{e}
\end{aligned}
$$

- Second case $\left(d R_{(a)}^{i}\right)$ : variation of the progressivity (with invariant flat rate component): $d \tau^{1}=0, d a_{i}=b(i) d a$ and $d a=-\Omega d \tau^{e}$

$$
\begin{aligned}
\frac{d R_{(a)}^{i}}{\frac{\alpha_{i}}{q_{i}} Y^{*}}= & Z \frac{\left(1-\tau^{i}\right)}{\left(1+\tau^{e}\right)} d \tau^{e} \\
& -\left[\frac{(Z-\eta)}{X} B_{I}+\frac{b(i)}{\left(1-\tau^{i}\right)}\right]\left(1-\tau^{i}\right) \Omega d \tau^{e}
\end{aligned}
$$




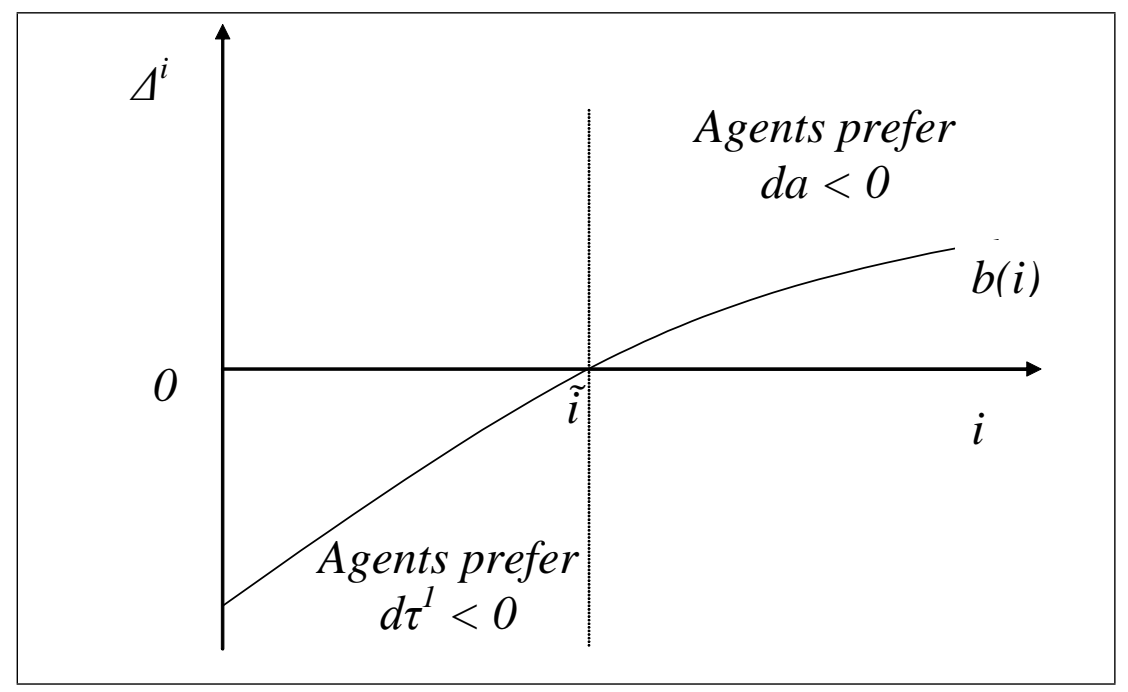

Figure 1: An Illustration of Workers Class Threshold in the French Case

The signs of these compensatory income variations depend on the values of the characteristics of the economy $\left(\lambda, e, b(i), \alpha_{i}\right)$ and of the initial tax rates $\left(\tau^{e}, \tau^{i}, a\right)$. We now compare the relative effects on welfare of the two tax policies. Consequently, we have to determine the sign of $\Delta^{i}=d R_{\left(\tau^{1}\right)}^{i}-d R_{(a)}^{i}$ for the workers of class $i$.

$$
\frac{\Delta^{i}}{\frac{\alpha_{i}}{q_{i}} Y^{*}}=-\left[\frac{(Z-\eta)}{X}(1-\lambda)\left(1-\tau^{i}\right)+1\right] \Lambda+\left[\frac{(Z-\eta)}{X} B_{I}\left(1-\tau^{i}\right)+b(i)\right] \Omega \gtreqless 0
$$

Using eq. 16 and $17\left(\frac{\Omega}{\Lambda}=\frac{1-\lambda}{B_{I}}\right)$, we find that this sign is equal to the sign of:

$$
b(i) \frac{1-\lambda}{B_{I}}-1=b(i) \frac{\Sigma \alpha_{i}}{\Sigma b(i) \alpha_{i}}-1
$$

Therefore the particular "average" workers' class $\tilde{\imath}$ defined above is indifferent between both policies $\left(\Delta^{\tilde{\imath}}=0\right)$. Each class of workers of a higher skill would prefer a decrease in the progressivity index, $d a<0$, and, conversely, each less skilled class of workers would prefer a decrease in the flat rate component of the wage tax, $d \tau^{1}<0$ (Figure 1 corresponding to the French case of a progressive labor tax). ${ }^{11}$

The result above suggests that, in the case where some workers' classes would be suffering from a deterioration of their welfare after the above tax reforms, an appropriate

\footnotetext{
${ }^{11}$ In order to simplify the graphics (especially Figure 3), we have chosen to plot figures as if all functions were continuously defined over a great number of workers classes.
} 
policy mix could be designed in order to leave each workers' class unharmed by the environmental tax reform : it would consist in an increase of the progressivity index together with a decrease of the flat rate component of the wage tax rate.

Assume that the balanced tax reform is defined by $d \tau^{1}<0$ and $d a=-\mu d \tau^{1}$ with $\mu>0$ hence $d a>0$. Such a compensation for the increase in the environmental tax rate will imply a greater decrease of $\tau^{1}$ than above because the degree of progressivity is raised.

Proposition 6 For economies where a decrease in the minimal wage rate does not suffice to re-establish the welfare of some class of worker, one can choose $\bar{\mu}$ in order to ensure that all classes will be better off with the environmental tax reform.

Proof. Let us specify the link implied by such a policy between the increase in the environmental tax rate and the decrease in the flat component of the wage tax.

$$
d \tau_{e}=-\frac{1}{\Lambda} d \tau^{1}-\frac{1}{\Omega} d a=-\frac{1}{\Omega}\left(\frac{\Omega}{\Lambda}-\mu\right) d \tau^{1}=-\frac{1}{\Omega}\left(\frac{1-\lambda}{B_{I}}-\mu\right) d \tau^{1}
$$

To ensure the existence of the new steady-state equilibrium, we have shown above (Ass. $2)$ that we need $-\frac{d a}{d \tau^{1}}=\mu<\frac{1-\lambda}{B_{I}}$. This condition also ensures the decrease of the flat rate component of the labor tax.

The compensatory income variation of the balanced mix policy is:

$$
\frac{d R_{(\mu)}^{i}}{\frac{\alpha_{i}}{q_{i}} Y^{*} d \tau^{e}}=\frac{\Omega}{\left(\frac{1-\lambda}{B_{I}}-\mu\right)}\left[\frac{1}{\Lambda} \frac{d R_{\tau^{1}}^{i}}{\frac{\alpha_{i}}{q_{i}} Y^{*} d \tau^{e}}+\mu\left[(Z-\eta) \frac{B_{I}}{X}\left(1-\tau^{i}\right)+b(i)-\frac{B_{I}}{1-\lambda} \frac{1}{\Lambda} Z \frac{\left(1-\tau^{i}\right)}{\left(1+\tau^{e}\right)}\right]\right]
$$

with $Z>0, X>0$, constants.

$-d R_{(\mu)}^{i} \lesseqgtr 0, \forall i=1, \ldots I$.

- $d R_{(\mu)}^{i}$ is not monotonous in $b(i)$, nor in $\mu, \forall i$.

- If $d R_{\left(\tau^{1}\right)}^{i}<0, \forall i=1, \ldots I$, all classes will be better off even with $\mu=0$.

If $\exists i, d R_{\left(\tau^{1}\right)}^{i}>0$, as the function $d R_{(\mu)}^{i}$ is bound for each $\mu$, there is one $\bar{\imath}$ which maximizes it (see Fig. 2 for a simple illustration):

$$
\bar{\imath}=\mathrm{INT}\left[\arg \max d R_{(\mu)}^{i}\right]
$$




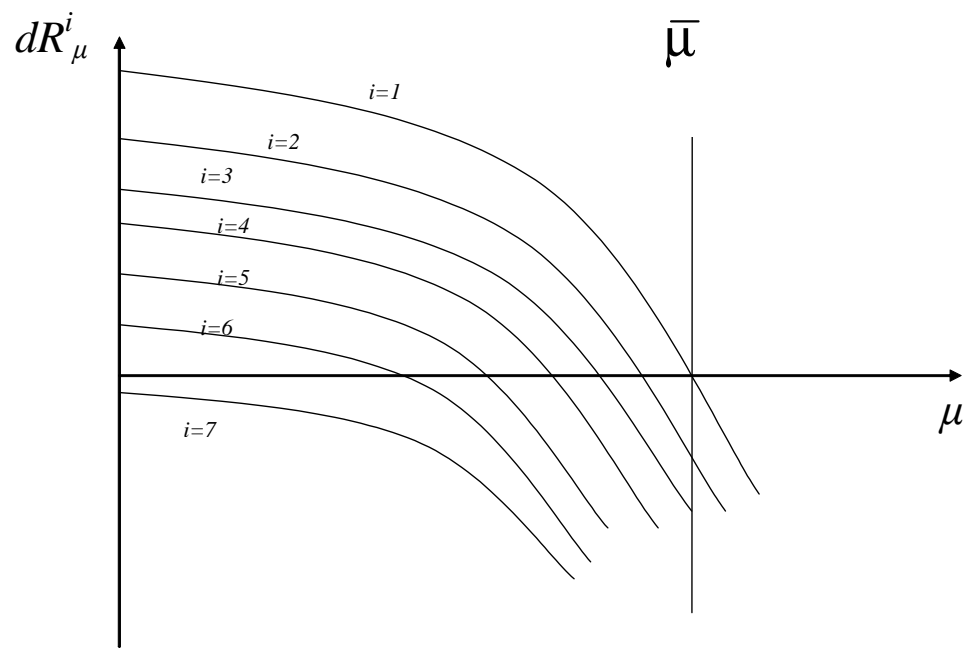

Figure 2: An Illustration of the Policy-Mix Criterion

One can choose $\bar{\mu}>0$ in order to nullify $d R_{(\mu)}^{\bar{n}}$ : it ensures that all classes will be better off (their compensatory income variations are all negative or null).

$$
\bar{\mu}=\frac{Z \frac{\left(1-\tau^{1}-a b(\bar{\imath})\right)}{\left(1+\tau^{e}\right)}-\Lambda\left[\left(1-\tau^{1}-a b(\bar{\imath})\right)(Z-\eta) \frac{(1-\lambda)}{X}+1\right]}{\Lambda\left[\frac{B_{I}}{1-\lambda} \frac{1}{\Lambda} Z \frac{\left(1-\tau^{1}-a b(\bar{\imath})\right)}{\left(1+\tau^{e}\right)}-(Z-\eta) \frac{B_{I}}{X}\left(1-\tau^{1}-a b(\bar{\imath})\right)-b(\bar{\imath})\right]}
$$

This policy mix aims to reduce the pre-existing distortions of the tax system, in a second-best world, but not to reach an optimal outcome. Therefore $\bar{\mu}$ comes from our Pareto-improving criterion but not from any optimality criterion.

It may be useful now to sum up the main mechanisms at work. The primary consequence of the environmental policy is the decrease of the pollution allowed by the decrease of the capital stock which also implies a reduction of the output. The cost of this environmental benefit consists in a fall in the gross wages of all agents. Nevertheless, for some groups of agents, this decline of the gross wages may be slowed by a decrease of their labor tax rate (for any group $i$ such that $b(i)<1 / \bar{\mu}$ ). The harmful effect of the fall in net wages on the total life-cycle consumption can be somehow counterbalanced by the drop in the capital stock, implying a rise of the interest rate which benefits the second-period consumption. 
The heterogeneity characteristics of the economy and the progressivity of the labor tax allow the government to obtain more revenues from the environmental policy. The decrease of the flat rate component can be greater without compromising the environmental benefit. Moreover, it enables the redistribution of welfare between the agents in order to fulfill our Pareto-improvement criterion.

Observe that even if the productivity is insensitive to pollution $(e=0)$ and/or if the pollution would affect the household's welfare in an additive way, our results would still be robust and contribute to the standard literature.

\section{The French Case: A Simple Empirical Illustration}

In order to illustrate the economic and welfare consequences of the environmental policy-mix, we choose some realistic values for the parameters of our theoretical model. Then, under these parameters' configuration, we compute the variations of compensatory income with respect to the class of agents $i$. Actually, we want to test the sensitivity of $\bar{\mu}$ with respect to the initial level of the labor tax rates. In more detail, we compute the values of the $d R_{\left(\tau^{1}\right)}^{i}, d R_{(a)}^{i}$ and $d R_{(\mu)}^{i}$ for different realistic values of $\tau^{i}$.

The initial tax system is supposed to be defined by the following values: $\tau^{e}=0.01$, $\tau^{1}=0.1$ and $a=0.1$. Concerning the environmental tax rate, it corresponds closely to the budget of the French Environment and Energy Management Agency (ADEME) which is entirely financed by environmental tax revenues. The flat rate component of the labor tax is the average income tax bearing on the first decile of taxable households. The design of the progressivity index is very general and fits well with many West European cases. More precisely, the wage tax rate writes $\tau^{i}=\tau^{1}+a b(i)$ with $b(i)=\rho \ln i$. We have considered 7 cases: $\rho=(0.01 ; 0.1 ; 0.5 ; 1 ; 1.5 ; 2 ; 3)$, see Fig. 3 . In particular, the French case corresponds to $\rho=1.5$.

The share of capital in total output is very common for developed countries $(\lambda=0.35)$ and we assume no particular preferences for the future $(\eta=0.5)$.

The environmental parameters are not easy to define. We fixed these values to some reasonable levels for this literature: $e=0.05, \phi=10, h=0.3$. Nevertheless, our results are robust to any changes in the values of these parameters. 


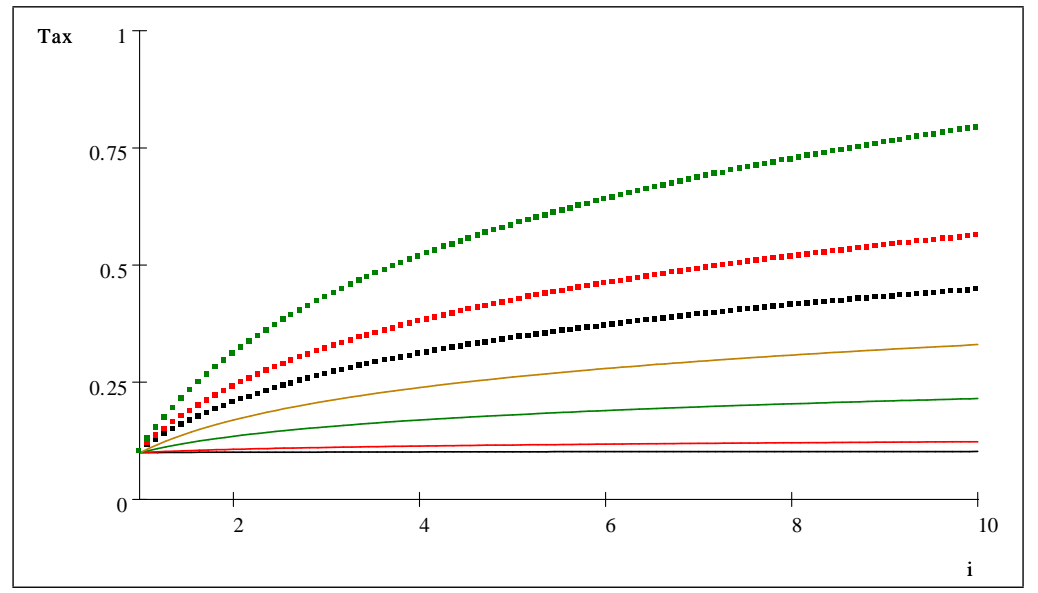

Figure 3: The Wage Tax Rates

Table I. - Labor Market Characteristics

\begin{tabular}{|c|c|c|c|c|c|c|c|c|c|c|}
\hline $\begin{array}{c}\text { Class } i \\
(I=10)\end{array}$ & 1 & 2 & 3 & 4 & 5 & 6 & 7 & 8 & 9 & 10 \\
\hline \hline$q_{i}$ & 0.1 & 0.1 & 0.1 & 0.1 & 0.1 & 0.1 & 0.1 & 0.1 & 0.1 & 0.1 \\
\hline$\alpha_{i}$ & 0.01 & 0.02 & 0.03 & 0.04 & 0.05 & 0.06 & 0.07 & 0.1 & 0.12 & 0.15 \\
\hline$w_{i} / w_{1}$ & 1 & 2 & 3 & 4 & 5 & 6 & 7 & 10 & 12 & 15 \\
\hline
\end{tabular}

Table I. presents the labor market characteristics. We assume an equi-distribution of the workers among the classes, such that $q_{i}=0.1, \forall i$ and $I=10$; hence each $i$ represents a decile of the corresponding class. We calibrated the shares in total output for workers of class $i\left(\alpha_{i}\right)$ such that the ratios of wages fit the French data. This ratio is equal to 15 for the highest class.

Table II. - The Policy Mix

\begin{tabular}{|c|c|c|c|c|c|c|c|}
\hline Prog. Case: & 1 & 2 & 3 & 4 & 5 & 6 & 7 \\
\hline \hline$\rho$ & 0.01 & 0.1 & 0.5 & 1 & 1.5 & 2 & 3 \\
\hline $\bar{\mu}$ & 0.1 & 0.11 & $\varnothing$ & $\varnothing$ & 0.26 & 0.23 & Tax inefficiency \\
\hline
\end{tabular}

We have numerically computed the value of $\mu$ required by the policy mix according to the different cases of progressivity (see Table II.). Concerning the low progressivity cases $\rho=0.01$ (resp. 0.1), the consequences on welfare of the alternative policies, measured by $d R_{\left(\tau^{1}\right)}^{i}$ and $d R_{(a)}^{i}$, show that the first class would be damaged by the policies, the second class is unaffected, and all the other classes would be better off. These policies are not Pareto improving. But, if the government can combine variations of the two parts of the labor tax rate and design a policy-mix system, he has to fix $\mu$ to 0.1 (resp. 0.11). Therefore, 
even the first class would benefit from the environmental tax policy. The increase in the welfare of the upper classes will be reduced, but is still high, comparatively to the lower classes.

For some intermediate levels of the labor tax rate $(\rho=0.5$ and 1$)$, it is impossible to define a policy compatible with the Pareto-improvement criterion. This configuration could be explained by the initial characteristics of the tax system. For these cases, the initial values are efficient, close to their optimal level. Hence, some agents would suffer a big decrease in their revenues that could not be compensated by the small gains of the agents who benefit from the tax policy. When the progressivity part of the labor tax rate is too high $(\rho=3)$, the tax system is obviously characterized by the inefficiency properties. Finally, for some reasonable values of the progressivity index $\rho=1.5$ (resp. 2), close to the French economic data, the alternative policies are unambiguously harmful for all the classes of workers. But, by fixing $\mu$ to 0.26 (resp. 0.23), the environmental policy would benefit all the agents. The environmental tax policy is then Pareto-improving and acceptable.

\section{Conclusion}

In this paper, we have shown that a budget-neutral environmental tax reform may result in a double dividend (defined as a decrease in pollution and an increase in the global economic welfare), even when the economy is characterized by heterogenous agents (old and young) and many worker classes (heterogenous labor). We have also emphasized that the conditions for the obtaining of a double dividend depend on the distributive properties of the labor taxes. Hence, we have shown that (i) an increase of the environmental tax deteriorates the welfare of all and is regressive, (ii) the low paid workers prefer an environmental tax reform balanced by a decrease in the flat rate component but the high paid workers prefer a decrease of the progressivity.

Even when the double dividend is not possible, the cost of the pollution regulation can be minimized by a new designing of the progressivity of the labor tax instead of a homogenous cut in the labor tax rates. We conclude that the distributive properties of the tax policy could be one of the instruments of fair internalization of the intergenerational externalities.

To a certain extent, our paper highlights the gap between economic efficiency and vertical equity and illustrates the problem of the aggregation of positive and negative 
compensatory variations: the usual method of aggregation gives a higher weight to the wealthiest classes and introduces a bias when assessing the desirability or the acceptability of any environmental tax reform.

\section{Aknowledgements}

This paper benefits from the financial support of the French National Research Agency (Grant ANR-09-BLAN-0350-01). We would like to thank two anonymous referees for precious suggestions. We would like to thank also participants to the 2008 AFSE Thematic Meeting in Environmental and Resource Economics, Toulouse (France), June 2008 and participants to the Environmental Economics Workshop, Corte (France), September 2008.

\section{Correspondence Details}

Mireille Chiroleu-Assouline (corresponding author)

Paris School of Economics - University Paris 1 Panthéon-Sorbonne

Centre d'Economie de la Sorbonne,

106-112 Bd de l'Hôpital 75647 PARIS Cedex 13

Tel : 33144078224

Fax : 33144078231

email : Mireille.Chiroleu-Assouline@univ-paris1.fr

Mouez Fodha

Paris School of Economics - University Paris 1 Panthéon-Sorbonne

Centre d'Economie de la Sorbonne,

106-112 Bd de l'Hôpital 75647 PARIS Cedex 13

Tel : 33144078221

Fax : 33144078231

email : Mouez.Fodha@univ-paris1.fr

\section{Appendix}

\section{Proof of local stability (Proposition 1)}

To prove the local stability part of the proposition, we linearize the dynamic system $(6,8)$ around the steady state. The linear approximation can be written in matrix form 
as:

$$
\begin{gathered}
{\left[\begin{array}{l}
K_{t+1}-K^{*} \\
P_{t+1}-P^{*} \\
x_{t+1}-x^{*} \\
z_{t+1}-z^{*}
\end{array}\right]=\Theta\left[\begin{array}{l}
K_{t}-K \\
P_{t}-P^{*} \\
x_{t}-x^{*} \\
z_{t}-z^{*}
\end{array}\right]} \\
\text { where } \Theta=\left[\begin{array}{cccc}
\lambda & 0 & -e(1-h) \frac{K^{*}}{(1-h) P^{*}+\phi K^{*}} & -e \phi \frac{K^{*}}{(1-h) P^{*}+\phi K^{*}} \\
\phi & 1-h & 0 & 0 \\
0 & 1 & 0 & 0 \\
1 & 0 & 0 & 0
\end{array}\right], x_{t+1}=P_{t} \text { and } \\
z_{t+1}=K_{t} \text {. The characteristic polynomial of } \Theta \text { is } \\
\mathcal{P}(\kappa)=\kappa^{2}\left[\kappa^{2}+\frac{\kappa(P(h(2-h)-\lambda(1-h)-1)-\phi K(1-h+\lambda))+\lambda P(1-h(2-h))+\phi K(\lambda(1-h)+e)}{P(1-h)+\phi K}\right.
\end{gathered}
$$

We know that $P^{*} / K^{*}=\phi / h$. So, we have the following properties $\mathcal{P}(0)=0, \mathcal{P}(1)=$ $\frac{\phi(1-\lambda+e)}{\frac{\phi}{h}(1-h)+\phi}>0$ and $\mathcal{P}(-1)=\frac{\frac{\phi}{h}((2-h)(1+\lambda)+h e)}{\frac{\phi}{h}(1-h)+\phi}>0$.

For sufficient conditions to local stability, we need that the modulus of each eigenvalue to be lower than one. We can decompose the characteristic polynomial into two parts: $\mathcal{P}(\kappa)=\mathcal{P}_{1}(\kappa) \cdot \mathcal{P}_{2}(\kappa)$, with $\mathcal{P}_{1}(\kappa)=\kappa^{2}$. Basically, the characteristic polynomial has two eigenvalues equal to $\kappa_{1}=\kappa_{2}=0$. Then we have to study the second part of $\mathcal{P}(\kappa)$ i.e. $\mathcal{P}_{2}(\kappa)=\kappa^{2}+\frac{\kappa(P(h(2-h)-\lambda(1-h)-1)-\phi K(1-h+\lambda))+\lambda P(1-h(2-h))+\phi K(\lambda(1-h)+e)}{P(1-h)+\phi K}$.

We already know that $\mathcal{P}(1)>0$ and $\mathcal{P}(-1)>0$, which induce that $\mathcal{P}_{2}(1)>0$ and $\mathcal{P}_{2}(-1)>0$. Regarding $\mathcal{P}_{2}(0)=\frac{\lambda P(1-h(2-h))+\phi K(\lambda(1-h)+e)}{P(1-h)+\phi K}=\frac{\lambda \frac{\phi}{h}(1-h(2-h))+\phi(\lambda(1-h)+e)}{\frac{\phi}{h}(1-h)+\phi}=$ $\lambda(1-h)+h e>0$. We now need $\mathcal{P}_{2}(0)<1$ which turns to $\lambda(1-h)+h e<1$, that is always true under Assumption 2. Hence, the steady state equilibrium $\left(K^{*}, P^{*}\right)$ is locally stable.

\section{References}

Antweiler, Werner, Brian R. Copeland, And M.Scott Taylor (2001): "Is free Trade Good for the Environment," American Economic Review, 91(4), p. 877-908. [4]

Baumol, William J. And Wallace E. OAtes (1988): The Theory of Environmental Policy. Cambridge University Press, 2nd edition,. [2,3]

Bloom, David E., David Canning, and Jaypee Sevilla (2004): "The Effects of Health on Economic Growth: A Production Function Approach," World Development, 32(1), p. 1-13. [4]

Bosello, Francesco, Roberto Roson, And Richard S.J. Tol (2006): "Economy-wide Estimates of the Implications of Climate Change: Human Health," Ecological Economics, 
58(3), p. 579-581. [4]

Bovenberg, A.Lans And Ruud A. De Mooij (1994): "Environmental Levies and Distortionary Taxation," American Economic Review, 84 (4), p. 1085-1089. [2,11]

Brown, Drusilla K., Alan V. Deardorff, and Robert M. Stern (1992): "A North American Free Trade Agreement: Analytical Issues and a Computational Assessment," World Economy, 15(1), p. 11-29. [4]

Chao Hung-po, and Stephen Peck (2000): "Greenhouse Gas Abatement: How Much? and Who Pays?," Resource and Energy Economics, 22(1), p. 1-20. [4]

Chiroleu-Assouline, Mireille And Mouez Fodha (2005): "Double Dividend with Involuntary Unemployment: Efficiency and Intergenerational Equity," Environmental and Resource Economics, 31(4), p. 389-403. [2,4]

Chiroleu-Assouline, Mireille And Mouez Fodha (2006): "Double Dividend Hypothesis, Golden Rule and Welfare Distribution," Journal of Environmental Economics and Management, 51(3), p. 323-335. [2,4,11]

Christainsen, Gregory B., And Thomas H. Tietenberg (1985): "Distributional and Macroeconomic Aspects of Environmental Policy," in Handbook of Natural Resource and Energy Economics, ed. by A. Kneese and J. Sweeney. Netherlands, Amsterdam: Elsevier, Vol. 1, p. 345-393 . [3]

De la Croix, David And Philippe Michel (2002): A Theory of Economic Growth: Dynamics and Policy in Overlapping Generations. Cambridge: Cambridge University Press. [10]

Diamond, Peter A. (1965): "National Debt in a Neoclassical Growth Model," American Economic Review, 55(1), p. 1126-1250. [6]

Elliott, Donald B., Bruce A. Ackerman, and John C. Millian (1985): "Toward a Theory of Statutory Evolution: The Federalization of Environmental Law," Journal of Law, Economics, and Organization, 1(2), p. 313-340. [3]

Gale, Lewis R. And Jose A. Mendez (1998): “The Empirical Relationship between Trade, Growth, and the Environment," International Review of Economics and Finance, $7(1)$, p. 53-61. [4]

Gollop, Franck M. and Gregory P. Swinand (1998): "From Total Factor to Total Resource Productivity: An Application to Agriculture," American Journal of Agricultural Economics, 80(3), p. 577-583. [4]

Goulder, Lawrence H. (1995): "Environmental Taxation and the "Double Dividend": 
A Reader's Guide," International Tax and Public Finance, 2(2), p. 157-183. [2,6,12]

Harrison, David Jr. (1995): Climate Change, Economic Instruments and Income Distribution. Paris, OECD. [3]

Hübler, Michael, Gernot Klepper, and Sonja Peterson (2008): "Costs of Climate Change - The Effects of Rising Temperatures on Health and Productivity," Ecological Economics, 68(1-2), p. 381-393. [4]

Konishi, Hideo and Fernando Perera-Tallo (1997): "Existence of steady-state equilibrium in an overlapping-generations model with production," Economic Theory, $9(3)$, p. 529-537. [10]

Ligthart, Jenny E. (1998): "The Macroeconomic Effects of Environmental Taxes : A Closer Look at the Feasibility of Win-Win Outcomes," International Monetary Fund, IMF Working Paper, 98/75, Washington. [2]

Metcalf, Gilbert E. (1999): "A Distributional Analysis of Green Tax Reforms," National Tax Journal, 52 (4), p. 655-682. [3]

Oates, Wallace E. (1991): "Pollution Charges As a Source of Public Revenues," Resources of the Future Discussion Paper, QE92-05. [2]

OECD (2008): Costs of Inaction on Key Environmental Challenges. Paris. [4]

Ostro, Bart D. (1983): "The Effects of Air Pollution on Work Loss and Morbidity," Journal of Environmental Economics and Management, 10(4), p. 371-382. [4]

PARry, Ian W.H. (1995): "Pollution Taxes and Revenue Recycling," Journal of Environmental Economics and Management, 29 (3), p. 64-77. [2]

Pearce, David W. (1991): "The Role of Carbon Taxes in Adjusting To Global Warming," The Economic Journal, 101(407), p. 938-948. [2]

Pervin, Tanjima, Ulf-G. Gerdtham, and Carl H. Hampus Lytkens (2008): "Societal Costs of Air Pollution-Related Health Hazards: A Review of Methods and Results," Cost Effectiveness and Resource Allocation, 6(19), doi:10.1186/1478-7547-6-19. [4]

Peskin, Henry M. (1978): "Environmental Policy and the Distribution of Benefits and Costs," in Current Issues in U.S. Environmental Policy ed. by Paul R. Portney. Baltimore, U.S.: J. Hopkins University Press for Resources for the Future, 144-163. [3]

Poterba, James M. (1993): "Global Warming Policy: A Public Finance Perspective," Journal of Economic Perspectives, 7(4), p. 47-63. [2]

Ruiz, Nicolas And Alain Trannoy (2008): "Le caractère régressif des taxes indirectes : les enseignements d'un modèle de microsimulation," Economie et Statistique, 413, p. 21- 
46. [3]

Samakovlis, Eva, Anni Huhtala, Tom Bellander, and Magnus Svartengren (2005): "Valuing Health Effects of Air Pollution - Focus on Concentration-response Functions," Journal of Urban Economics, 58(2), p. 230-249. [4]

Terkla, David (1984): "The Efficiency Value of Effluent Tax Revenues," Journal of Environmental Economics and Management, 11(2), p. 107-123. [2]

Williams, Roberton C. III (2002): "Environmental Tax Interactions when Pollution Affects Health or Productivity," Journal of Environmental Economics and Management, 44(2), p. 261-270. [4]

Williams, Roberton C. III (2003): "Health Effects and Optimal Environmental Taxes," Journal of Public Economics, 87(2), p. 323-335. [4] 